\title{
The impact of oxidized serum albumin on the oncotic pressure and hydration status of peritoneal dialysis patients
}

This article was published in the following Dove Press journal:

Therapeutics and Clinical Risk Management

24 March 2016

Number of times this article has been viewed

\section{Kamal Hassan ${ }^{1,2}$ \\ Batya Kristal ${ }^{1,2}$ \\ Fadi Hassan ${ }^{3}$ \\ Saad Abo Saleh ${ }^{4}$ \\ Regina Michelis ${ }^{5}$}

'Faculty of Medicine in the Galilee, Bar-Ilan University, Safed, Israel; ${ }^{2}$ Peritoneal Dialysis Unit, Department of Nephrology and Hypertension, Galilee Medical Center, Nahariya, Israel; ${ }^{3}$ Sackler Faculty of Medicine, Tel Aviv University, Tel Aviv, Israel; ${ }^{4}$ Department of Urology, Galilee Medical Center, Nahariya, Israel; ${ }^{5}$ Eliachar Research Laboratory, Galilee Medical Center, Nahariya, Israel
Correspondence: Kamal Hassan Department of Nephrology and Hypertension, Peritoneal Dialysis Unit, Galilee Medical Center, PO Box 2I, Nahariya 22100, Israel

Tel +972507887913

Fax +972 49107482

Email drkamalh@hotmail.com
Objective: Hypoalbuminemia, fluid overload (FO), and oxidative stress (OS) may be related to cardiovascular morbidity and mortality in peritoneal dialysis (PD) patients. OS produces molecular modifications of serum albumin that interfere with its quantification by the commonly used bromocresol green assay. This study evaluated the impact of oxidized serum albumin (OSA) on oncotic pressure (OP) and hydration status.

Patients and methods: Twenty-four stable hypoalbuminemic PD patients were enrolled in the study. After performing physical examination, assessment of the hydration status using a whole-body bioimpedance spectroscopy technique was performed, and blood samples were drawn for determination of OP, serum albumin levels, and OSA.

Results: Extracellular to total body water $(\mathrm{E} / \mathrm{TBW})$ ratio was higher in patients with $\mathrm{FO} \geq 1.5 \mathrm{~L}$ with or without edema than in patients with FO $<1.5 \mathrm{~L}(P \leq 0.043)$. E/TBW ratio was higher in patients with $\mathrm{FO} \geq 1.5 \mathrm{~L}$ and edema compared to those with $\mathrm{FO} \geq 1.5 \mathrm{~L}$ but without edema $(P=0.004)$. OP was significantly higher in patients with $\mathrm{FO} \geq 1.5 \mathrm{~L}$ and without edema compared to those with $\mathrm{FO} \geq 1.5 \mathrm{~L}$ and with edema $(P<0.001)$. Albumin-detection index (ADI) in patients with $\mathrm{FO} \geq 1.5 \mathrm{~L}$ and without edema was similar to $\mathrm{ADI}$ in patients with $\mathrm{FO}<1.5 \mathrm{~L}(P=0.520)$. ADI was significantly lower in patients with $\mathrm{FO} \geq 1.5 \mathrm{~L}$ and without edema compared to those with $\mathrm{FO} \geq 1.5 \mathrm{~L}$ and edema $(P=0.034)$. E/TBW ratio correlated positively with the $\mathrm{ADI}(r=0.60$, $P=0.001)$ and inversely with the OP $(r=-0.54, P=0.002)$.

Conclusion: Overhydration may be clinically undetectable in PD patients. Assessing the hydration status and measuring the total serum albumin levels, including the oxidized fraction, should be considered in evaluating hydration status in PD patients.

Keywords: peritoneal dialysis, oncotic pressure, oxidized serum albumin, hydration status

\section{Introduction}

Hypoalbuminemia is a common finding among peritoneal dialysis (PD) patients and is considered an important measure of malnutrition and inflammation that may be related to cardiovascular $(\mathrm{CV})$ morbidity and mortality in this population. ${ }^{1-3}$ Fluid overload (FO) is a common problem in PD patients that is associated independently and significantly with mortality in dialysis patients. ${ }^{4}$ Oxidative stress (OS) in dialysis patients produces molecular modifications of serum albumin such as carbonylation, formation of advanced glycoxidation end products, and advanced oxidation protein products (AOPP) ${ }^{5-8}$ Serum albumin oxidation disturbs its biological functions due to conformational alterations (such as increased negative charge and exposure of hydrophobic regions), decreased antioxidant activity, and decreased drug binding. ${ }^{6,8-10}$ These modifications of serum albumin interfere with its detection and quantification 
by the commonly used bromocresol green (BCG) assay. ${ }^{11}$ The albumin-detection index (ADI) can be used to assess the oxidized serum albumin (OSA) fraction. ${ }^{11}$ To the best of our knowledge, the impact of OSA on oncotic pressure (OP) and hydration status has not been investigated in $\mathrm{PD}$ patients.

\section{Patients and methods}

Twenty-four (17 males and seven females) hypoalbuminemic PD patients on maintenance PD (14 on continuous ambulatory PD and 10 on automated PD) for a period of more than 1 year were enrolled in the study. All participants had serum albumin levels $<3.5 \mathrm{~g} / \mathrm{dL}$, as measured by BCG assay. The study protocol was approved by the Institutional Helsinki Committee of Galilee Medical Center, Naharyia, Israel, and written informed consent was obtained from all participants. Any evidence of infection, malignancy, liver disease, gastrointestinal disturbances, or severe hyperparathyroidism was considered exclusion criteria. After obtaining full medical history and performing physical examination, we accurately assessed hydration status using a whole-body bioimpedance spectroscopy (BIS) technique and drew blood samples from all participants to determine OP, serum albumin levels (by $\mathrm{BCG}$ ), and OSA (by applying the ADI).

\section{Hydration status assessment}

The hydration status was assessed by whole-body BIS technique using a Fresenius Medical Care Body Composition Monitor device (Fresenius Medical Care, Bad Homburg, Germany). ${ }^{12}$ This method is considered to be practical, safe, simple, repetitive, reliable, accurate, and noninvasive. FO and hydration status indices were determined. Regarding the differences in body size and hydration status, the hydration status index (edema index) extracellular to total body water ratio (E/TBW ratio) was used as an independent and comparable indicator of the hydration status.

\section{OP measurements in sera}

OP was measured in sera using a colloid osmometer (Wescor, Logan, UT, USA), which operates using a membrane with a cut-off of $30 \mathrm{kDa}$; thus, the measured OP relates only to proteins with a molecular mass $>30 \mathrm{kDa}$.

\section{Determination of "albumin-detection index" in sera}

Albumin was purified from sera using Cibacron Blue 3GA Agarose (CB3GA). CB3GA was inserted into a SigmaPrep spin column and washed four times by addition of $10 \mathrm{mM}$ Tris $(\mathrm{pH} \mathrm{8.0)}$ and short centrifugations $(8,000 \times g$,
10 seconds). Serum $(150 \mu \mathrm{L})$ was added to the washed CB3GA, incubated at room temperature for 10 minutes, and centrifuged $(12,000 \times g, 1$ minute). This step was repeated. The twice-depleted serum was discarded, and elution buffer $(150 \mu \mathrm{L}, 10 \mathrm{mM}$ Tris $\mathrm{pH} 8.0$, and $1.5 \mathrm{M} \mathrm{NaCl})$ was added to the column. After 10 minutes incubation, the albumin samples were eluted by centrifugation $(12,000 \times g, 1$ minute $)$ into a new collection tube. To deplete immunoglobulin contaminations, $100 \mu \mathrm{L}$ of the eluted albumin sample was incubated (with shaking) for 3 hours at $4{ }^{\circ} \mathrm{C}$ with 20 $\mu \mathrm{L}$ (washed and diluted into $900 \mu \mathrm{L} \mathrm{H}_{2} \mathrm{O}$ ) of protein $\mathrm{A} / \mathrm{G}$ Ultralink Resin (Thermo Scientific, Waltham, MA, USA). The resin-bound immunoglobulins were discarded by centrifugation. The supernatant was concentrated by SPEEDVAC centrifugation ( $~ 3$ hours). ADI is defined as the ratio between the readout of the albumin-specific assay BCG to the total albumin concentration in the fraction as determined at optical density $280 \mathrm{~nm}\left(\mathrm{OD}_{280}\right) .{ }^{11}$ The BCG assay was performed according to the instructions provided with the Aeroset chemical analyzer (Abbott Laboratories, Abbott Park, IL, USA). ADI = Serum albumin/(Serum albumin + OSA). Thus, ADI =1 when the fractionated albumin shows similar concentrations when measured by the BCG assay or at $\mathrm{OD}_{280}$. When the serum albumin concentration, measured by the BCG assay, decreases as a result of the presence of modifications of albumin, the ADI will be $<1 .{ }^{11}$

\section{Statistical methods}

Statistical analysis was carried out using SPSS (IBM SPSS Statistics version 21, IBM Corporation, Armonk, NY, USA) software. $P$-value $<0.05$ was considered to be significant. Continuous variables are reported as mean and standard deviations, and categorical variables as frequencies and percentages. The Fisher's exact test was used to compare the frequencies between the study groups, including the presence of diabetes, sex, race, PD modality, and peritoneal membrane characteristics. The Kruskal-Wallis and Wilcoxon rank sum tests were used to compare the differences between the study groups, including age, body mass index (BMI), PD vintage, residual renal function (RRF), ultrafiltration (UF), $K / V$ (a dimensionless index that measures the fractional urea clearance during dialysis: $K$ is the blood urea clearance [liters per hour], $t$ is the dialysis length [hour], $V$ is the distribution volume of urea [liters]), FO, E/TBW ratio, ADI, OP, serum albumin, total serum albumin, and hemoglobin levels. Pearson's correlation coefficient test was used to describe associations between $\mathrm{E} / \mathrm{TBW}$ ratio, $\mathrm{ADI}, \mathrm{OP}$, and total serum albumin. 


\section{Results}

All study groups were comparable in their age, BMI, PD modality, PD vintage, RRF, UF, peritoneal membrane characteristics, and $K / v$ (Table 1). Among 24 participants, five patients had $\mathrm{FO}<1.5 \mathrm{~L}$ without edema, 12 patients had $\mathrm{FO} \geq 1.5 \mathrm{~L}$ without edema, and seven patients had FO $\geq 1.5 \mathrm{~L}$ and edema (Table 2). FO was similar in groups $\mathrm{B}$ and $\mathrm{C}$ (patients with $\mathrm{FO} \geq 1.5 \mathrm{~L}$ without or with edema; $P=0.395$ ) (Table 2). E/TBW ratio was higher in patients with $\mathrm{FO} \geq 1.5 \mathrm{~L}$ with or without edema than in patients with $\mathrm{FO}<1.5 \mathrm{~L}$ $(P \leq 0.043$; Table 2$)$. E/TBW ratio was significantly higher in patients with $\mathrm{FO} \geq 1.5 \mathrm{~L}$ and edema compared to those with $\mathrm{FO} \geq 1.5 \mathrm{~L}$ but without edema ( $P=0.004$; Table 2$)$. OP in patients with $\mathrm{FO} \geq 1.5 \mathrm{~L}$ and without edema was similar to $\mathrm{OP}$ in patients with $\mathrm{FO}<1.5 \mathrm{~L}(P=0.092)$. OP was significantly lower in patients with $\mathrm{FO} \geq 1.5 \mathrm{~L}$ and edema compared to those with $\mathrm{FO} \geq 1.5 \mathrm{~L}$ and without edema $(P<0.001$; Table 2). ADI in patients with $\mathrm{FO} \geq 1.5 \mathrm{~L}$ and without edema was similar to ADI in patients with $\mathrm{FO}<1.5 \mathrm{~L}(P=0.520)$. ADI was significantly lower in patients with $\mathrm{FO} \geq 1.5 \mathrm{~L}$ and without edema compared to those with $\mathrm{FO} \geq 1.5 \mathrm{~L}$ and edema ( $P=0.034$; Table 2). Serum albumin and hemoglobin levels were similar in all study groups ( $P \geq 0.112$; Table 2$)$. E/TBW ratio correlated positively and significantly with the ADI ( $r=0.60, P=0.001$; Figure 1 ). The mean total serum albumin was similar in nonedematous patients whether they had FO or not $(P=0.185$; Table 2$)$. The mean total serum albumin level was significantly lower in edematous and overhydrated patients ( $P=0.013$; Table 2 ). A positive correlation was found between $\mathrm{OP}$ and total serum albumin $(r=0.54, P=0.003$;
Figure 2). An inverse correlation was found between $\mathrm{OP}$ and E/TBW ratio ( $r=-0.54, P=0.002$; Figure 3 ).

\section{Discussion}

Although the majority (79.2\% [19/24]) of PD patients with hypoalbuminemia have FO $\geq 1.5 \mathrm{~L}$, most $(63.2 \%$ [12/19]) of them did not have any clinical evidence of overhydration. In other words, most PD patients have subclinical overhydration. Those overhydrated and hypoalbuminemic patients who did not have clinical signs of overhydration by physical examination were found to have OP $>20 \mathrm{mmHg}$. They maintain their OP because they have higher levels of OSA that can be assessed by the ADI but cannot be detected when the serum albumin is measured by BCG assay. Thus, because FO may be clinically undetectable by physical examination, accurate methods for assessing hydration status, such as those based on BIS, together with accurate measurement of the serum albumin levels, including the oxidized fraction, should be used to evaluate hydration status in PD patients. These are the main findings in this study.

Three groups of hypoalbuminemic PD patients with similar mean serum albumin levels were identified (Figure 4). Group A included patients without clinical signs of FO (edema), $\mathrm{FO}<1.5 \mathrm{~L}, \mathrm{E} / \mathrm{TBW}$ ratio $<0.5$, OP $>20 \mathrm{mmHg}$, and $\mathrm{ADI} \leq 0.5$. Group $\mathrm{B}$ included patients without clinical signs of $\mathrm{FO}$ (edema), $\mathrm{FO} \geq 1.5 \mathrm{~L}, \mathrm{E} / \mathrm{TBW}$ ratio $<0.5$, $\mathrm{OP}>20 \mathrm{mmHg}$, and $\mathrm{ADI} \leq 0.5$. In groups $\mathrm{A}$ and $\mathrm{B}$, the OP was maintained as a result of the relatively high levels of OSA, as reflected by the low ADI. Group C included patients with clinical signs of $\mathrm{FO}$ (edema), $\mathrm{FO} \geq 1.5 \mathrm{~L}, \mathrm{E} / \mathrm{TBW}$ ratio $>0.5$,

Table I The characteristics of the study population

\begin{tabular}{|c|c|c|c|c|c|c|c|c|}
\hline Variables & $\begin{array}{l}\text { All patients } \\
\text { enrolled in the } \\
\text { study }\end{array}$ & $\begin{array}{l}\text { Group A } \\
\text { Patients with } \\
\text { FO }<\text { I.5 L and } \\
\text { without edema }\end{array}$ & $\begin{array}{l}\text { Group B } \\
\text { Patients with } \\
\text { FO } \geq I .5 \mathrm{~L} \text { and } \\
\text { without edema }\end{array}$ & $\begin{array}{l}\text { Group C } \\
\text { Patients with } \\
\text { FO } \geq I .5 \mathrm{~L} \text { and } \\
\text { with edema }\end{array}$ & Pabc & Pab & $P^{a c}$ & $P^{\mathrm{bc}}$ \\
\hline n (\%) & $24(100)$ & $5(20.8)$ & $12(50)$ & $7(29.2)$ & & & & \\
\hline Age (years) & $56.1 \pm 12.9$ & $55.6 \pm 21.1$ & $57.3 \pm 9.2$ & $54.6 \pm 13.2$ & $0.842 *$ & $0.430 * *$ & $0.438 *$ & $0.26 \mathrm{I} * *$ \\
\hline Males/females (n)\%/(n)\% & (I5)70.8/(9)29.2 & (3)60/(2)40 & $(7) 58.3 /(5) 4 I .7$ & (5)7I.4/(2) 28.6 & $0.308 * * *$ & $0.128 * * *$ & $0.318^{* * *}$ & $0.474 * * *$ \\
\hline Diabetes mellitus (n)\% & $10(41.7)$ & $2(40)$ & $5(4 \mid .7)$ & $3(42.9)$ & $0.870 * * *$ & $0.686 * * *$ & $0.500 * * *$ & $0.430 * * *$ \\
\hline BMI $\left(\mathrm{kg} / \mathrm{m}^{2}\right)$ & $28.5 \pm 5.3$ & $26.5 \pm 2.8$ & $29.1 \pm 5.7$ & $28.9 \pm 6.4$ & $0.625^{*}$ & $0.191 * *$ & $0.265^{*}$ & $0.459 * *$ \\
\hline CAPD/APD (n)\%/(n)\% & $(14) 58.3 /(10) 41.7$ & (3)60/(2)40 & $(7) 58.3 /(5) 4 I .7$ & $(4) 57.1 /(3) 42.9$ & $1.00 * * *$ & $0.686 * * *$ & $0.689 * * *$ & $0.663 * * *$ \\
\hline $\mathrm{PD}$ vintage & $24.8 \pm 14.4$ & $24.6 \pm 18.9$ & $25.2 \pm 15.5$ & $24.2 \pm 10.8$ & $0.983^{*}$ & $0.430 * *$ & $0.369 *$ & $0.492 * *$ \\
\hline $\operatorname{RRF}\left(\mathrm{mL} / \mathrm{min} / \mathrm{l} .73 \mathrm{~m}^{2}\right)$ & $5.3 \pm 1.0$ & $5.2 \pm 0.8$ & $5.3 \pm 0.9$ & $5.3 \pm 1.4$ & $0.974 *$ & $0.45 \mathrm{I} * *$ & $0.438^{*}$ & $0.442 * *$ \\
\hline UF (mL) & $\mathrm{I}, 829.2 \pm 5 \mid 5.4$ & $1,820 \pm 517$ & $\mathrm{I}, 800 \pm 435$ & $1,886 \pm 699$ & $0.846^{*}$ & $0.292 * *$ & $0.394^{*}$ & $0.363^{*}$ \\
\hline PET:HA/LA (n)\%/(n)\% & $(12) 50 /(12) 50$ & (3)60/(2)40 & $(6) 50 /(6) 50$ & (3)42.9/(4)57.I & $1.00 * * *$ & $0.563 * * *$ & $0.500 * * *$ & $0.570 * * *$ \\
\hline$K_{t} / V$ & $1.91 \pm 0.08$ & $1.92 \pm 0.08$ & $1.9 \pm 0.09$ & $1.91 \pm 0.09$ & $0.857^{*}$ & $0.436 * *$ & $0.588 *$ & $0.435^{*}$ \\
\hline
\end{tabular}

Notes: *Kruskal-Wallis test, **Wilcoxon rank sum, ***Fisher's exact test. Values are presented as mean \pm standard deviation.

Abbreviations: FO, fluid overload; BMI, body mass index; CAPD, continuous ambulatory peritoneal dialysis; APD, automated peritoneal dialysis; PD, peritoneal dialysis; RRF, residual renal function; UF, ultrafiltration; PET, peritoneal equilibration test; HA, high average; LA, low average; $K / V$, a dimensionless index that measures the fractional urea clearance during dialysis; $K$, blood urea clearance (L/h); $t$, dialysis length (hour); $V$, distribution volume of urea (L); $P^{\text {abc }}$, statistical significance between groups A, B, and C; $P^{\text {ab }}$, statistical significance between groups $A$ and $B$; Pac, statistical significance between groups $A$ and $C$; $P^{\text {bc }}$, statistical significance between groups $B$ and $C$. 
Table 2 The hydration status parameters, OP, ADI, serum albumin measured by BCG, and hemoglobin levels in PD patients according to FO and the presence/absence of edema

\begin{tabular}{|c|c|c|c|c|c|c|c|c|}
\hline Variables & $\begin{array}{l}\text { All patients enrolled } \\
\text { in the study }(n=24)\end{array}$ & $\begin{array}{l}\text { Patients with } \\
\text { FO }<1.5 \text { L } \\
\text { without edema } \\
\text { Group A }(n=5)\end{array}$ & $\begin{array}{l}\text { Patients with } \\
\text { FO } \geq I .5 \mathrm{~L} \\
\text { without edema } \\
\text { Group B }(n=12)\end{array}$ & $\begin{array}{l}\text { Patients with } \\
\text { FO } \geq I .5 \mathrm{~L} \\
\text { with edema } \\
\text { Group C }(n=7)\end{array}$ & $P^{a b c, *}$ & $P^{a b, * *}$ & $\mathbf{P}^{\mathrm{ac}, * * *}$ & $P^{\mathrm{bc}, * * *}$ \\
\hline $\mathrm{FO}(\mathrm{L})$ & $2.21 \pm 1.53$ & $0.20 \pm 0.28$ & $2.72 \pm 1.37$ & $2.79 \pm 1.13$ & 0.001 & 0.001 & 0.001 & 0.395 \\
\hline E/TBW ratio & $0.5 I \pm 0.07$ & $0.45 \pm 0.06$ & $0.49 \pm 0.04$ & $0.57 \pm 0.08$ & 0.006 & 0.043 & 0.015 & 0.004 \\
\hline $\mathrm{OP}(\mathrm{mmHg})$ & $22.2 \pm 3.0$ & $22.7 \pm I .4$ & $23.8 \pm 2.1$ & $18.9 \pm 2.7$ & 0.003 & 0.092 & 0.014 & $<0.001$ \\
\hline ADI & $0.53 \pm 0.12$ & $0.48 \pm 0.06$ & $0.50 \pm 0.10$ & $0.62 \pm 0.15$ & 0.089 & 0.520 & 0.024 & 0.034 \\
\hline Total serum albumin ${ }^{\#}$ & $5.04 \pm 0.97$ & $5.73 \pm 0.17$ & $5.31 \pm 0.99$ & $4.21 \pm 0.84$ & 0.025 & 0.185 & 0.001 & 0.013 \\
\hline Serum albumin $(\mathrm{g} / \mathrm{dL})$ & $2.6 \pm 0.4$ & $2.7 \pm 0.4$ & $2.6 \pm 0.3$ & $2.5 \pm 0.5$ & 0.452 & 0.112 & 0.230 & 0.379 \\
\hline Hemoglobin (g/dL) & $11.0 \pm 0.8$ & $11.36 \pm 0.84$ & II. $.04 \pm 0.74$ & $10.6 \pm 0.94$ & 0.389 & 0.185 & 0.080 & 0.317 \\
\hline
\end{tabular}

Notes: *Kruskal-Wallis test. **Wilcoxon rank sum test. Values are presented as mean \pm standard deviation. ${ }^{*}$ Total serum albumin $=$ serum albumin measured by BCG assay + oxidized serum detected by ADI.

Abbreviations: OP, oncotic pressure; ADI, albumin-detection index; BCG, bromocresol green; PD, peritoneal dialysis; FO, fluid overload; E/TBW, extracellular to total body water ratio (edema index); Pabc, statistical significance between groups A, B, and C; $P^{\text {ab }}$, statistical significance between groups $A$ and $B$; $P^{\text {ac }}$, statistical significance between groups $A$ and $C$; Pbc, statistical significance between groups $B$ and $C$.

$\mathrm{OP}<20 \mathrm{mmHg}$, and $\mathrm{ADI}>0.5$. In this group, the OP is low as a result of the "true" hypoalbuminemia and relatively low levels of OSA reflected by the high ADI.

In nonedematous patients, whether they had FO or not, the serum albumin levels measured by BCG assay were similar to those in edematous patients. However, the total serum albumin (including the oxidized fraction) calculated by the equation:

$\begin{gathered}\text { Total serum } \\ \text { lbumin }(\mathrm{g} / \mathrm{dL})\end{gathered}=\frac{\text { Serum albumin measured by BCG assay }}{\mathrm{ADI}}$

was significantly lower in edematous (overhydrated) patients because these patients had lower levels of modified serum albumin, as it reflected by their higher ADI, and lower OP that, eventually, lead to the development of fluid over load and edema.

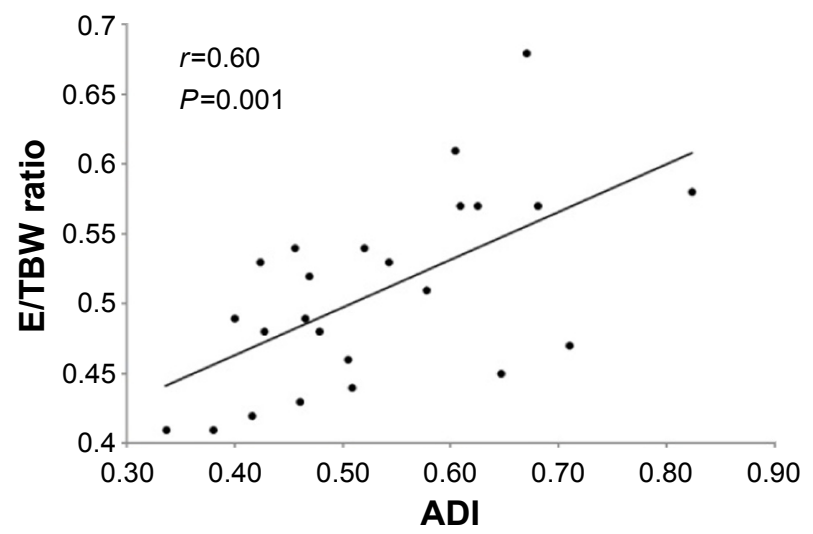

Figure I The correlation between E/TBW ratio and the ADI.

Abbreviations: E/TBW, extracellular to total body water; ADI, albumindetection index.
Hypoalbuminemia, usually defined as serum albumin levels $<3.5 \mathrm{~g} / \mathrm{dL}$, is a common finding in PD and has been attributed to nutritional deficiencies, peritoneal albumin losses, and inflammation. Hypoalbuminemia is prevalent in clinical states associated with chronic inflammation and OS, including PD. One study showed that low levels of serum albumin are partially due to oxidative modifications of albumin, which impair its detection and quantification by the standard laboratory albumin assay BCG. ${ }^{11}$ ADI in hemodialysis patients is significantly lower compared with controls, correlating inversely with OS markers (serum AOPP and glycoxidized serum albumin) and positively with serum albumin levels. ${ }^{1-3}$ Previous studies evaluated ADI as a general marker for oxidative modifications of serum albumin by means of in vitro and in vivo measuring of ADI. ${ }^{11,13}$ The results of these studies demonstrated that ADI is an albuminoxidation marker. On the basis of these studies, the impact of modified serum albumin on hydration status parameters

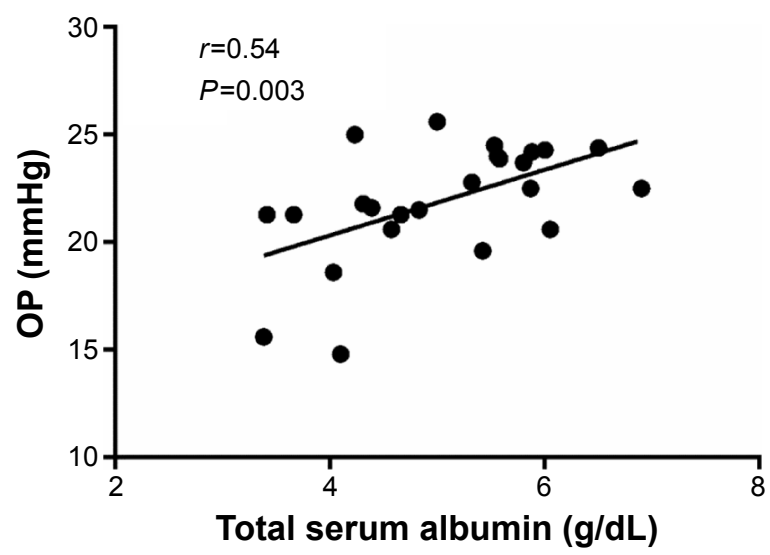

Figure 2 The correlation between OP and total serum albumin. Abbreviation: OP, oncotic pressure. 


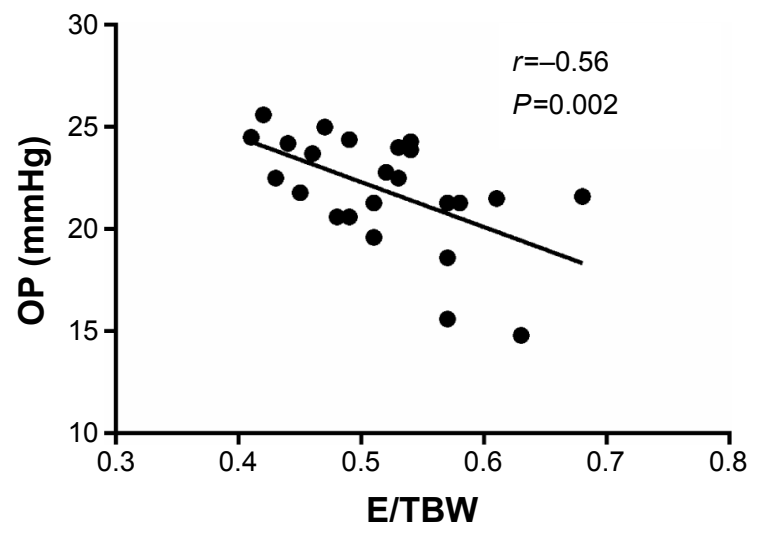

Figure 3 The correlation between $\mathrm{OP}$ and E/TBW ratio. Abbreviations: OP, oncotic pressure; E/TBW, extracellular to total body water.

was evaluated in this study by using the ADI marker. Other markers such as serum AOPP and carbonyl content are considered more general markers, reflecting the oxidation of all plasma proteins, including proteins that have little effect on the hydration status.

Hypoalbuminemia is considered an important predictor of CV morbidity and mortality among PD patients. ${ }^{3,14,15}$ Increased OS and high levels of oxidized/modified serum albumin contribute to $\mathrm{CV}$ complications via various molecular mechanisms, such as overproduction of apolipoprotein B and nitric oxide pool, affecting neutrophils and endothelial cells, and through decreasing the antioxidant capacity..$^{8,9,13,16-23}$ These mechanisms suggest that OSA is a pathogenic mediator that has the ability to initiate and accelerate the development of atherosclerosis. ${ }^{24}$

Usually, studies utilized the serum albumin levels for epidemiological surveys. Without measuring the oxidative status of serum albumin, it is impossible to distinguish between "true" and "apparent" hypoalbuminemia. OP correlates with total serum albumin, even when modified or oxidized(Figure 2). Hypoalbuminemia associated with low ADI indicates the presence of pathogenic modified albumin molecules that are capable of triggering endothelial dysfunction. ${ }^{24}$ The modified serum albumin, by triggering and injuring various cells such as those of the endothelium, may contribute to micro- and macrovascular complications. ${ }^{3}$ Modifications of serum albumin in vivo have been reported in various diseases, including diabetes mellitus (types 1 and 2), renal failure, endstage renal disease, and coronary artery disease. .,6,25 $^{2}$

Hypoalbuminemia may impede the ability to maintain volume status, leading to the development of FO, elevated blood pressure, and activated inflammatory processes. Hypoalbuminemia, hypertension, and chronic inflammation are considered promoting factors for the development of atherosclerosis. ${ }^{26,27}$

A high proportion of participants ( $\geq 40 \%$ ) have diabetes mellitus. Although glycation of albumin has the most severe

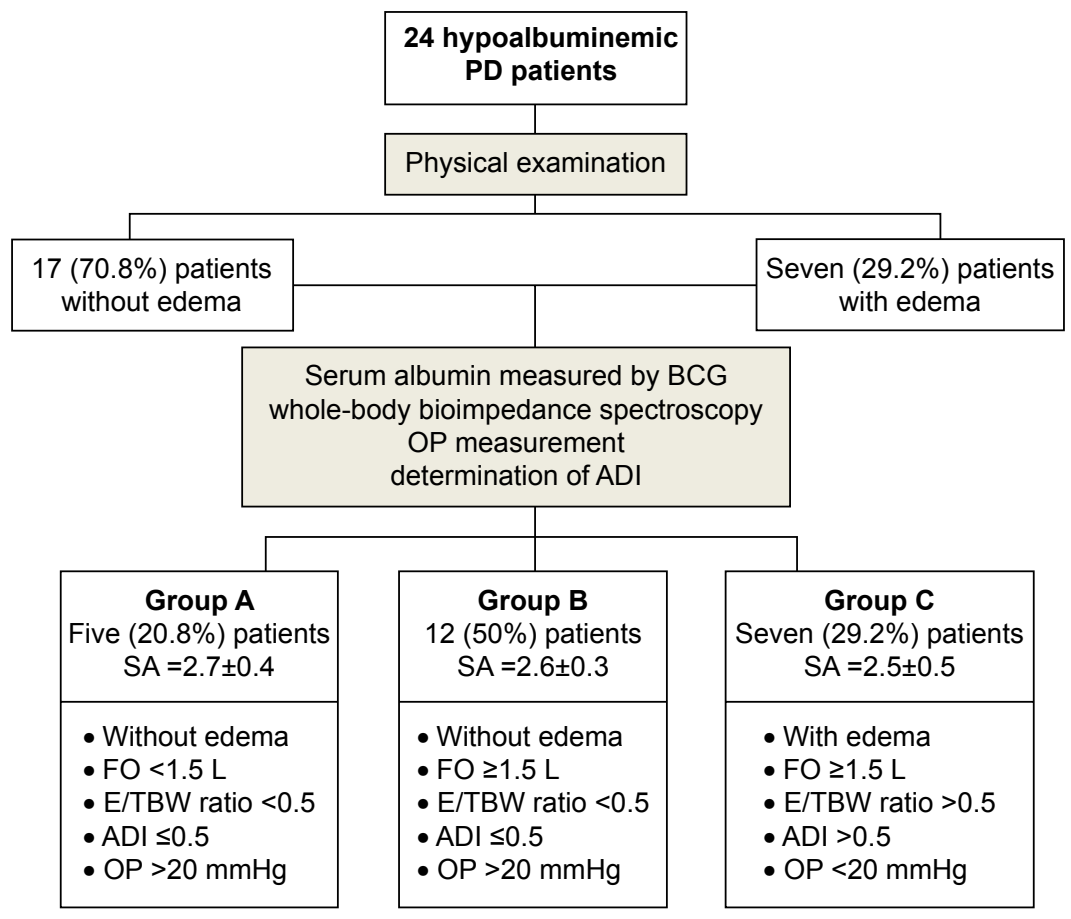

Figure 4 Three groups of hypoalbuminemic PD patients with similar mean serum albumin levels were identified according to the presence of clinical signs of overhydration (edema), mean FO, E/TBW ratio, OP, and ADI.

Abbreviations: ADI, albumin-detection index; BCG, bromocresol green; E/TBW, extracellular to total body water; FO, fluid overload; OP, oncotic pressure; PD, peritoneal dialysis; SA, serum albumin. 
impact on albumin detection by the bromcresol method, $\mathrm{HbA}_{1 \mathrm{c}}$ reflects modifications of hemoglobin, not serum albumin. ${ }^{11,13}$ Recent studies demonstrated that glycated albumin levels and $\mathrm{HbA}_{1 \mathrm{c}}$ values are not in perfect agreement. ${ }^{28,29}$ Thus, the values of ADI would not necessarily correlate with $\mathrm{HbA}_{1 \mathrm{c}}$. In this study, no correlation was found between ADI and $\mathrm{HbA}_{1 \mathrm{c}}$.

OP depends not only on serum albumin content but also on other serum proteins. Although albumin comprises only $55 \%-60 \%$ of the plasma proteins, at least $80 \%$ of the OP is determined by serum albumin. The OP was measured by a colloid osmometer membrane with a cut-off of $30 \mathrm{kDa}$. Thus, the measured OP is related to all proteins with a molecular weight $>30 \mathrm{kDa}$.

The positive correlation between E/TBW ratio and ADI, as is illustrated in Figure 1, and the higher ADI in patents with more severe symptoms, as is listed in Table 2, interestingly, means that patients with less severe symptoms have higher levels of modified serum albumin. This finding can certainly be explained by the fact that in patients with higher ADI, measurements of serum albumin by BCG assay are more accurate and that the hypoalbuminemia is appropriately assessed. Therefore, hypoalbuminemia under these circumstances favor the development of substantial fluid excess as it was assessed accurately by the BIS. Conversely, in patients with relatively lower ADI, the measurements of serum albumin by BCG assay are inaccurate because it is impossible to detect the modified serum albumin fraction by the BCG assay, and therefore, the hypoalbuminemia is actually less severe and associated with better hydration status.

On the basis of the results of this study, the absence of peripheral edema in overhydrated hypoalbuminemic PD patients can be attributed to higher OP that results from higher total serum albumin, including the oxidized fraction that is assessed by applying the ADI. Although the overhydration in these patients is subclinical, they still have increased risk for developing $\mathrm{CV}$ complications that are considered the main cause of morbidity and mortality in the PD population. Because the OSA is capable of triggering endothelial dysfunction and promoting the initiation of atherosclerosis and CV disease, hypoalbuminemia should be carefully evaluated and elucidated. ${ }^{16,30}$

This study highlights the highly prevalent subclinical overhydration among PD patients that may lead to the development of CV complications. Considering the poor prognosis associated with overhydration in PD patients, periodic assessment of hydration status using accurate BIS and detection of the oxidized albumin by applying the ADI render these measurements potential therapeutic tools for the detection and management of subclinical overhydration in PD populations. Identifying relevant patients and performing real-time interventions to decrease the fluid excess and the inflammatory process may contribute to the improvement of their clinical outcomes.

\section{Limitations}

This study was performed in one center and included a relatively small number of patients. Because ADI gives no direct information on the type of albumin modification, lipids bound to albumin might also interfere with BCG assay. However, the findings may provide useful information for further, multicenter randomized controlled trials to determine the role of modified serum albumin on the hydration status in PD patients.

\section{Conclusion}

Overhydration states may be clinically undetectable in PD patients. Accurate methods, such as BIS, for assessing the hydration status and accurate measurement of the total serum albumin levels (including the oxidized fraction) should be considered in evaluating the hydration status of PD patients.

\section{Disclosure}

The authors report no conflicts of interest in this work.

\section{References}

1. Beddhu S, Kaysen GA, Yan G, et al. HEMO Study Group. Association of serum albumin and atherosclerosis in chronic hemodialysis patients. Am J Kidney Dis. 2002;40(4):721-727.

2. Cooper BA, Penne EL, Bartlett LH, Pollock CA. Protein malnutrition and hypoalbuminemia as predictors of vascular events and mortality in ESRD. Am J Kidney Dis. 2004;43(1):61-66.

3. Iseki K, Kawazoe N, Fukiyama K. Serum albumin is a strong predictor of death in chronic dialysis patients. Kidney Int. 1993;44:115-119.

4. Paniagua R, Ventura MD, Avila-Díaz M, et al. NT-proBNP, fluid volume overload and dialysis modality are independent predictors of mortality in ESRD patients. Nephrol Dial Transplant. 2010;25(2):551-557.

5. Himmelfarb J, McMonagle E. Albumin is the major plasma protein target of oxidant stress in uremia. Kidney Int. 2001;60(1):358-363.

6. Lim PS, Cheng YM, Yang SM. Impairments of the biological properties of serum albumin in patients on haemodialysis. Nephrology (Carlton). 2007; 12(1):18-24.

7. Mera K, Anraku M, Kitamura K, et al. Oxidation and carboxy methyl lysine-modification of albumin: possible involvement in the progression of oxidative stress in hemodialysis patients. Hypertens Res. 2005; 28(12):973-980.

8. Witko-Sarsat V, Friedlander M, Capeillère-Blandin C, et al. DescampsLatscha, advanced oxidation protein products as a novel marker of oxidative stress in uremia. Kidney Int. 1996;49:1304-1313.

9. Mera K, Anraku M, Kitamura K, Nakajou K, Maruyama T, Otagiri M. The structure and function of oxidized albumin in hemodialysis patients: its role in elevated oxidative stress via neutrophil burst. Biochem Biophys Res Commun. 2005;334:1322-1328. 
10. Anraku M, Yamasaki K, Maruyama T, Kragh-Hansen U, Otagiri M. Effect of oxidative stress on the structure and function of human serum albumin. Pharm Res. 2001;18:632-639.

11. Michelis R, Kristal B, Snitkovsky T, Sela S. Oxidative modifications impair albumin quantification. Biochem Biophys Res Commun. 2010; 401(1):137-142.

12. Hur E, Gungor O, Musayev O, et al. Bioimpedance spectroscopy for the detection of hypervolemia in peritoneal dialysis patients. Adv Perit Dial. 2011;27:65-70.

13. Michelis R, Kristal B, Zeitun T, et al. Albumin oxidation leads to neutrophil activation in vitro and inaccurate measurement of serum albumin in patients with diabetic nephropathy. Free Radic Biol Med. 2013;60: 49-55.

14. Kalantar-Zadeh K, Kopple JD, Block G, Humphreys MH. A malnutrition-inflammation score is correlated with morbidity and mortality in maintenance hemodialysis patients. Am J Kidney Dis. 2001;38:1251-1263.

15. Shah NR, Dumler F. Hypoalbuminaemia - a marker of cardiovascular disease in patients with chronic kidney disease stages II-IV. Int J Med Sci. 2008;5(6):366-370.

16. Colombo G, Clerici M, Giustarini D, Rossi R, Milzani A, Dalle-Donne I. Redox albuminomics: oxidized albumin in human diseases. Antioxid Redox Signal. 2012;17:1515-1527.

17. Himmelfarb J, Stenvinkel P, Ikizler TA, Hakim RM. The elephant in uremia: oxidant stress as a unifying concept of cardiovascular disease in uremia. Kidney Int. 2002;62:1524-1538.

18. Rashid G, Benchetrit S, Fishman D, Bernheim J. Effect of advanced glycation end-products on gene expression and synthesis of TNF-alpha and endothelial nitric oxide synthase by endothelial cells. Kidney Int 2004;66:1099-1106.

19. Rubenstein DA, Maria Z, Yin W. Glycated albumin modulates endothelial cell thrombogenic and inflammatory responses. J Diabetes $\mathrm{Sci}$ Technol. 2011;5:703-710.
20. Ishima Y, Hoshino H, Shinagawa T, et al. S-guanylation of human serum albumin is a unique posttranslational modification and results in a novel class of antibacterial agents. J Pharm Sci. 2012;101:3222-3229.

21. Opländer C, Rösner J, Gombert A, et al. Redox-mediated mechanisms and biological responses of copper-catalyzed reduction of the nitrite ion in vitro. Nitric Oxide. 2013;35C:152-164.

22. Greenblatt DJ. Reduced serum albumin concentration in the elderly: a report from the Boston collaborative drug surveillance program. $J$ Am Geriatr Soc. 1979;27:20-22.

23. Ceriello A, Motz E. Is oxidative stress the pathogenic mechanism underlying insulin resistance, diabetes, and cardiovascular disease? The common soil hypothesis revisited. Arterioscler Thromb Vasc Biol. 2004;24:816-823.

24. Ahmed N. Advanced glycation endproducts - role in pathology of diabetic complications. Diabetes Res Clin Pract. 2005;67:3-21.

25 . Rondeau $\mathrm{P}$, Bourdon $\mathrm{E}$. The glycation of albumin: structural and functional impacts. Biochimie. 2011;93:645-658.

26. Monfared A1, Salari A, Kazemnezhad E, et al. Association of left ventricular hypertrophy with high-sensitive C-reactive protein in hemodialysis patients. Int Urol Nephrol. 2013;45(6):1679-1686.

27. van der Walt C, Malan L, Uys AS, Malan NT. Low grade inflammation and ECG left ventricular hypertrophy in urban African males: the SABPA study. Heart Lung Circ. 2013;22(11):924-929.

28. Kim MK, Yun KJ, Kwon HS, Baek KH, Song KH. Discordance in the levels of hemoglobin A1C and glycated albumin: calculation of the glycation gap based on glycated albumin level. J Diabetes Complications. Epub December 28, 2015.

29. Yoon HJ, Lee YH, Kim KJ, et al. Glycated albumin levels in patients with type 2 diabetes increase relative to $\mathrm{hba}_{1 \mathrm{c}}$ with time. Biomed Res Int. 2015;2015:576306.

30. Talmor Y, Golan E, Benchetrit S, et al. Calcitriol blunts the deleterious impact of advanced glycation end products on endothelial cells. Am J Physiol Renal Physiol. 2008;294:1059-1064.
Therapeutics and Clinical Risk Management

\section{Publish your work in this journal}

Therapeutics and Clinical Risk Management is an international, peerreviewed journal of clinical therapeutics and risk management, focusing on concise rapid reporting of clinical studies in all therapeutic areas, outcomes, safety, and programs for the effective, safe, and sustained use of medicines. This journal is indexed on PubMed Central, CAS,

\section{Dovepress}

EMBase, Scopus and the Elsevier Bibliographic databases. The manuscript management system is completely online and includes a very quick and fair peer-review system, which is all easy to use. Visit http://www.dovepress.com/testimonials.php to read real quotes from published authors. 